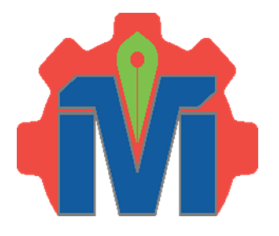

JMI Vol. 38 No. 2 Desember 2016

METAL INDONESIA

Journal homepage:

http://www.jurnalmetal.or.id/index.php/jmi

p-issn: $0126-3463$

e-issn : 2548-673X

\title{
PEMBUATAN PADUAN NAFeB UNTUK APLIKASI BAHAN BAKU MAGNET PERMANEN
}

\section{NdFeB ALLOYS MAKING FOR PERMANENT MAGNET RAW MATERIALS APPLICATIONS}

\author{
Shinta Virdhian ${ }^{1}$, Djoko Hadi Prayitno ${ }^{2}$, Sina Jamilah ${ }^{1}$ \\ ${ }^{1}$ Balai Besar Logam dan Mesin, Kementerian Perindustrian \\ Jl. Sangkuriang No. 12 Bandung 40135 \\ ${ }^{2}$ Pusat Sains dan Teknologi Nuklir, Badan Tenaga Nuklir Nasional, \\ Jalan Taman Sari No.7 Bandung - Jawa Barat \\ Email: shinta_va@yahoo.com
}

\begin{abstract}
Abstrak
Penggunaan magnet NdFeB menjadi semakin luas seiring dengan makin tingginya kesadaran tentang pemanasan global. Penelitian ini bertujuan untuk mengembangkan proses pembuatan paduan logam tanah jarang yang dapat digunakan sebagai bahan baku magnet permanen serta memperoleh serbuk paduan logam tanah jarang dengan sifat magnetik yang baik. Dalam penelitian ini dilakukan metode casting-powder metalurgi. Proses peleburan dengan menggunakan Argon Arc Melting Furnace dapat menghasilkan ingot yang cukup homogen, hanya saja faktor loss dari logam-logam yang dilebur harus diperhitungkan sehingga komposisi yang didapatkan sesuai dengan yang diinginkan. Persentase fasa magnetik dari paduan yang dihasilkan sudah mendekati paduan komersial (> $80 \%)$. Proses Annealing dapat meningkatkan jumlah fasa magnetik dalam paduan NdFeB. Penambahan zircon dalam paduan $\mathrm{NdFeB}$ dapat meningkatkan kestabilan fasa $\mathrm{Nd}_{2} \mathrm{Fe}_{14} \mathrm{~B}$ sehingga tidak diperlukan proses perlakuan panas untuk meningkatkan sifat magnetik. Sifat magnetik yang masih rendah harus ditingkatkan dengan memperbaiki kondisi operasi (vakum atau gas inert).
\end{abstract}

Kata kunci: logam tanah jarang, magnet permanen, $\mathrm{NdFeB}$,

\begin{abstract}
The used of NdFeB magnets become wider along with the higher awareness of global warming. This research aims to develop rare earth metal making process that can be used as raw material of permanent magnet, and obtain rare earth metal powder with good magnetic properties. This research was conducted casting-powder metallurgy method. Melting process using Argon Arc Melting Furnace can produce ingot fairly homogenous, but loss factor from melting metals have to be calculated so that the composition obtained in accordance with expected. Magnetic phrase percentage of the resulting alloy is approaching commercial alloys (> $80 \%$ ). Annealing process can increase magnetic phrase in $\mathrm{NdFeB}$ alloy. The addition of zircon in $\mathrm{NdFeB}$ alloy can improve $\mathrm{Nd}_{2} \mathrm{Fe}_{14} \mathrm{~B}$ phase stability so it is not necessary to perform heat treatment process to improve magnetic properties. Magnetic properties that still low have to be improved by improve the operation conditions (vacuum or inert gas).
\end{abstract}

Keywords: rare earth metal, permanent magnet, $N d F e B$

\section{PENDAHULUAN}

Logam Tanah Jarang (LTJ) atau dikenal dengan istilah rare earth merupakan salah satu sumber daya alam yang tidak dapat diperbaharui dan mineral langka yang banyak digunakan sebagai bahan dasar utama dalam industri elektronik dan industri militer. Dalam sistem periodik unsur, kelompok logam tanah jarang merupakan kelompok lantanida yang memiliki anggota 14 unsur yaitu: La-Ce-Pr-Nd-Pm-SmEu-Gd-Tb-Dy-Ho-Tr-Tm-Yb-Lu. Logam grup 
lain yang sering berasosiasi dalam mineral yang sama adalah Sc-Y.

Pada saat ini, kendaraan listrik dan hibrid mendapatkan banyak perhatian berkaitan dengan pengurangan penggunaan bahan bakar fosil. Kedua jenis kendaraan ini menggunakan listrik yang memerlukan permanent magnet atau generator. Dibandingkan dengan magnet permanen konvensional, magnet permanen yang mengandung logam tanah jarang memiliki sifat magnet yang lebih baik yaitu koersiviti, remanence, dan nilai maksimum energi produk (Matsuura, 2006). Neodymium adalah unsur logam tanah jarang yang banyak digunakan untuk aplikasi magnet. Neodymium diprediksi akan mendominasi dalam industri magnet di masa depan. Dua alasan utama penggunaan Neodymium secara luas dalam industri magnet adalah ketersediaannya yang relatif banyak dan sifat magnetiknya yang superior. $\mathrm{NdB}$, salah satu jenis magnet logam tanah jarang, digunakan secara luas dalam bidang motor industri.

Penggunaan magnet $\mathrm{NdFeB}$ menjadi semakin luas seiring dengan semakin tingginya kesadaran tentang pemanasan global. Di masa mendatang penggunaan $\mathrm{NdFeB}$ semakin meluas ke peralatan seperti mecin cuci, pendingin dan lain-lain yang bertujuan untuk meningkatkan efisiensi energi dan konservasi energi. Market yang paling potensial adalah untuk aplikasi otomotif sehingga dapat mengurangi berat, keselamatan dan kenyamanan.

Kegiatan ini bertujuan untuk mengembangkan proses pembuatan paduan logam tanah jarang untuk bahan baku magnet permanen dan memperoleh serbuk paduan logam tanah jarang dengan sifat magnetik yang baik. Dengan demikian, diharapkan dapat meningkatkan nilai tambah sumber daya alam mineral yang terdapat di Indonesia. Penguasaan teknologi pemprosesan logam tanah jarang diharapkan juga dapat menjadi pendukung pengembangan teknologi maju di Indonesia.

\section{METODOLOGI}

Pada penelitian ini dilakukan proses peleburan dan pemaduan logam tanah jarang untuk aplikasi permanen magnet. Proses pembuatan paduan menggunakan metode casting diikuti powder metalurgi. Diagram alir dari percobaan dapat dilihat pada Gambar 1 dan Gambar 2.

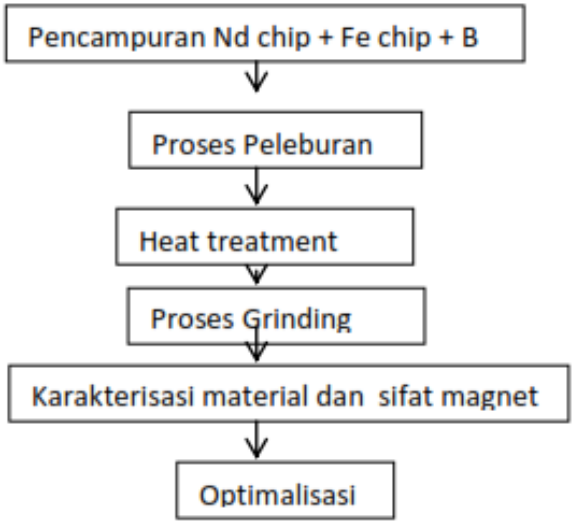

Gambar 1. Diagram alir pembuatan serbuk $\mathrm{NdFeB}$ dengan metode powder metalurgi

Dalam kegiatan ini dilakukan peleburan untuk berbagai komposisi. Ke dalam paduan $\mathrm{NdFeB}$ juga ditambahkan zircon sebagai paduan untuk memodifikasi struktur mikro dan sifat magnetik. Komposisi nominal dari paduan beserta analisis yang dilakukan dapat dilihat pada Tabel 1 Komposisi nominal paduan $\mathrm{NdFeB}$ beserta analisis yang dilakukan. Perlakuan panas dilakukan pada kondisi argon $1000{ }^{\circ} \mathrm{C}$. Proses quenching dilakukan dalam media air dan waktu tahan untuk proses annealing 4 jam.

Tabel 1. Komposisi nominal paduan $\mathrm{NdFeB}$ beserta analisa yang dilakukan

\begin{tabular}{|c|c|}
\hline No & Komposisi \\
\hline 1 & $\mathrm{Nd}_{14} \mathrm{Fe}_{78} \mathrm{~B}_{8}$ \\
\hline 2 & $\mathrm{Nd}_{14} \mathrm{Fe}_{76} \mathrm{~B}_{8 \mathrm{r}} \mathrm{Zr}_{2}$ \\
\hline 3 & As Strip (China) \\
\hline
\end{tabular}




\section{HASIL DAN PEMBAHASAN}

\section{Analisis SEM}

Ingot Nd-Fe-B hasil solidifikasi pada proses peleburan dengan arc melting furnace diamati dengan SEM untuk melihat morfologi fasa utama dan fasa kedua. Analisis kuantitatif fasafasa yang ada dilakukan dengan back scattered imaged maupun EDX. Pada Tabel 2 dibandingkan hasil observasi struktur mikro dengan SEM untuk komposisi $\mathrm{Nd}_{14} \mathrm{Fe}_{78} \mathrm{~B}_{8}$, $\mathrm{Nd}_{12} \mathrm{Fe}_{78} \mathrm{~B}_{8} \mathrm{Zr}_{2}$ dan strip casting dalam kondisi as cast, as quench dan anneal. Hasil pengamatan SEM menunjukkan bahwa semua memiliki fasa utama $\mathrm{Nd}_{2} \mathrm{Fe}_{14} \mathrm{~B}$. Annealing membuat struktur menjadi lebih halus untuk paduan $\mathrm{Nd}_{14} \mathrm{Fe}_{78} \mathrm{~B}_{8}$ dan strip casting, sedangkan untuk paduan $\mathrm{Nd}_{14} \mathrm{Fe}_{76} \mathrm{~B}_{8} \mathrm{Zr}_{2}$ mengalami pertumbuhan butir menjadi lebih besar. Hasil EDS element mapping menujukkan elemen zircon banyak terdistribusi di batas butir mensubstitusi sebagian $\mathrm{Nd}$, kemungkinan fasa yang tersebut adalah $\mathrm{Zr}_{3} \mathrm{Fe}$. Sedangkan untuk paduan $\mathrm{Nd}_{14} \mathrm{Fe}_{78} \mathrm{~B}_{8}$, di daerah batas butir terlihat daerah kaya Nd seperti yang terlihat pada EDS mapping paduan $\mathrm{Nd}_{14} \mathrm{Fe}_{78} \mathrm{~B}_{8}$ (Tabel 4) yang menunjukkan warna putih pada batas butir. Hasil quenching tidak menunjukkan perubahan yang significant dari hasil as cast sehingga dapat dikatakan tidak ada peningkatan stuktur yang berarti. Pada paduan $\mathrm{NdFeB}$ biasanya muncul fasa kedua berupa alpha Ferrite ataupun $\mathrm{Zr}_{3} \mathrm{~F}$ untuk penambahan $\mathrm{Zr}$.

Pengamatan SEM juga dilakukan pada paduan dengan komposisi $\quad \mathrm{Fe}_{82} \mathrm{Nd}_{11} \mathrm{~B}_{6} \mathrm{Zr}_{1}$, $\mathrm{Fe}_{82} \mathrm{Nd}_{10} \mathrm{~B}_{6} \mathrm{Zr}_{2}, \quad \mathrm{Fe}_{82} \mathrm{Nd}_{9} \mathrm{~B}_{6} \mathrm{Zr}_{3}$, yang memiliki kandungan $\mathrm{Nd}$ yang lebih kecil daripada komposisi sebelumnya. Hasil pengamatan SEM menunjukkan perbedaan yang jelas antara fasa utama $\mathrm{Nd}_{2} \mathrm{Fe}_{14} \mathrm{~B}$ dengan fasa kedua yaitu $\mathrm{Zr}_{3} \mathrm{Fe}$. Pada Tabel 3 fasa utama $\mathrm{Nd}_{2} \mathrm{Fe}_{14} \mathrm{~B}$ ditunjukkan dengan warna terang dan fasa alpha $\mathrm{Fe}$ dengan warna gelap. Dalam paduan Nd-Fe-B, jumlah alpha $\mathrm{Fe}$ harus dikurangi karena dapat menurunkan sifat magnetik. Penambahan $\mathrm{Zr}$ menyebabkan semakin berkurangnya fasa magnetik $\mathrm{Nd}_{2} \mathrm{Fe}_{14} \mathrm{~B}$ dan bertambahnya fasa ke dua $\mathrm{Zr}_{3} \mathrm{Fe}$.
Tabel 2. Sampel yang mengalami perlakuan panas

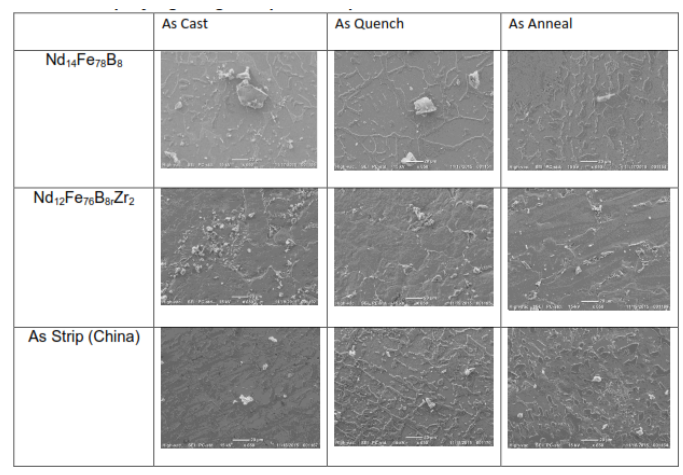

\section{Analisis Struktur Kristal XRD}

Identifikasi fasa-fasa yang terbentuk pada ingot hasil peleburan dilakukan dengan XRD menggunakan radiasi $\mathrm{Cu} \mathrm{K} \alpha(\lambda=1.54056 \mathrm{~A})$ yang beroperasi pada tegangan $40 \mathrm{KV}$ dan arus generator $55 \mathrm{~mA}$. Celah pemancar dan penerima yang digunakan masing masing adalah $1^{0}$ dan $0.1^{\circ}$. Parameter XRD ini menghasilkan pola difraksi sinar $\mathrm{x}$ yang bertujuan untuk mengidentifikasi fasa. Identifikasi dilakukan dengan membandingkan pola difraksi sinar $\mathrm{x}$ yang dihasilkan dengan pola difraksi fasa $\mathrm{Nd}_{2} \mathrm{Fe}_{14} \mathrm{~B}$.

Pada Tabel 3 ditampilkan pola difraksi sinar $-\mathrm{X}$ untuk paduan komposisi $\mathrm{Nd}_{14} \mathrm{Fe}_{78} \mathrm{~B}_{8}$, $\mathrm{Nd}_{12} \mathrm{Fe}_{78} \mathrm{~B}_{8} \mathrm{Zr}_{2}$ dan strip casting dalam kondisi as cast, as quench dan anneal. Puncak-puncak difraksi didentifikasikan sebagai puncak-puncak fasa $\mathrm{Nd}_{2} \mathrm{Fe}_{14} \mathrm{~B}$ serta adanya puncak-puncak tambahan dari alpha ferrite (pada sudut $2 \theta=$ 44.58) dan fasa $\mathrm{Zr}_{3} \mathrm{~F}$. Sampel Strip menunjukkan peak apha $\mathrm{Fe}$ yang cukup tinggi. Hal ini disebabkan karena pendinginan yang cepat pada waktu pembuatan paduan. Pada kondisi annealing dan quenching dapat terlihat bahwa puncak difraksi alpha Fe pada sampel strip casting berkurang. Ringkasan hasil analisis quantitative dari analisis XRD dapat dilihat pada Tabel 6 dan diilustrasikan pada Gambar 3. Paduan $\mathrm{Nd}_{14} \mathrm{Fe}_{78} \mathrm{~B}_{8}$ hasil peleburan (as cast) memiliki kandungan fasa utama $\mathrm{Nd}_{2} \mathrm{Fe}_{14} \mathrm{~B}$ sebanyak 75 persen. Setelah di-annealing fasa magnetik yang dihasilnya bertambah menjadi 80 persen sehingga dapat disimpulkan bahwa annealing dapat memperbaiki sifat magnetik dari paduan $\mathrm{Nd}_{14} \mathrm{Fe}_{78} \mathrm{~B}_{8}$. 
Tabel 3. Hasil analisa XRD

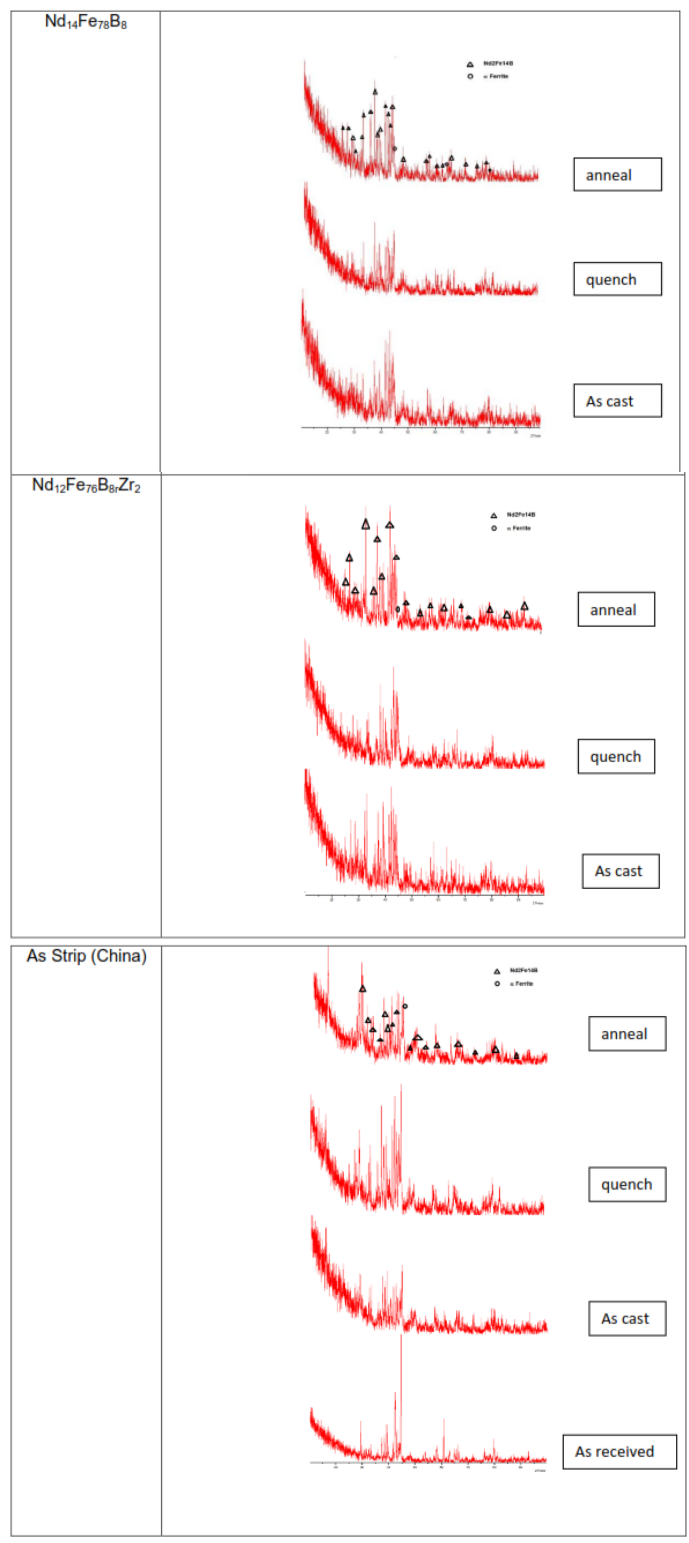

Untuk paduan dengan penambahan zircon $\left(\mathrm{Nd}_{14} \mathrm{Fe}_{78} \mathrm{~B}_{8} \mathrm{Zr}_{2}\right)$ memiliki fasa magnetik yang cukup tinggi (>80\% pada kondisi as cast). Proses perlakuan panas yang dilakukan tidak mengubah jumlah fasa magnetik secara significant, sehingga dapat dikatakan bahwa zircon membuat fasa utama menjadi lebih stabil. Untuk sampel strip casting sendiri menunjukkan perbaikan sifat magnetik dengan perlakuan panas yang diberikan dengan bertambahnya secara significant fasa magnetik setelah proses annealing.

Dalam perhitungan quantitative fasa dilakukan dengan menggunakan software $\mathrm{X}$ powder. Karena cukup kompleksnya puncak difraksi dari fasa-fasa dalam paduan Nd-Fe-B maka dilakukan perbandingan perhitungan dengan menggunakan software Match dan dilakukan proses refining data software gsas. Untuk paduan $\mathrm{Nd}_{14} \mathrm{Fe}_{78} \mathrm{~B}_{8}$ hasil perhitungan menggunakan software Match menujukkan fasa magnetik $95.5 \%$ dan fasa kedua $4.5 \%$.

Tabel 4. Analisis kuantitatif menggunakan XRD

\begin{tabular}{|l|l|c|c|c|}
\hline \multicolumn{1}{|c|}{ Komposisi } & \multicolumn{1}{|c|}{ Kondisi } & $\begin{array}{c}\text { alpha Ferrite } \\
\text { (\% wt) }\end{array}$ & $\begin{array}{c}\mathrm{Nd}_{2} \mathrm{Fe}_{14} \mathrm{~B} \\
(\% \mathrm{wt})\end{array}$ & $\begin{array}{c}\mathrm{Zr} \mathrm{F}_{3} \mathrm{Fe} \\
(\% \mathrm{wt})\end{array}$ \\
\hline $\mathrm{Nd}_{14} \mathrm{Fe}_{78} \mathrm{~B}_{8}$ & As Cast & 24.9 & 75.1 & \\
\hline & As Quench & 31.4 & 68.6 & \\
\hline & Anneal & 19.1 & 80.9 & \\
\hline $\mathrm{Nd}_{14} \mathrm{Fe}_{70} \mathrm{~B}_{8} \mathrm{Zr}_{2}$ & As Cast & 13 & 81.5 & 5.5 \\
\hline & As Quench & 11.9 & 82.1 & 6 \\
\hline & Anneal & 17 & 78.3 & 4.7 \\
\hline strip cast & As Cast & 37.3 & 62.7 & \\
\hline & As Quench & 37.1 & 62.9 & \\
\hline & Anneal & 30.4 & 69.6 & \\
\hline & As Received & 60.7 & 39.3 & \\
\hline
\end{tabular}

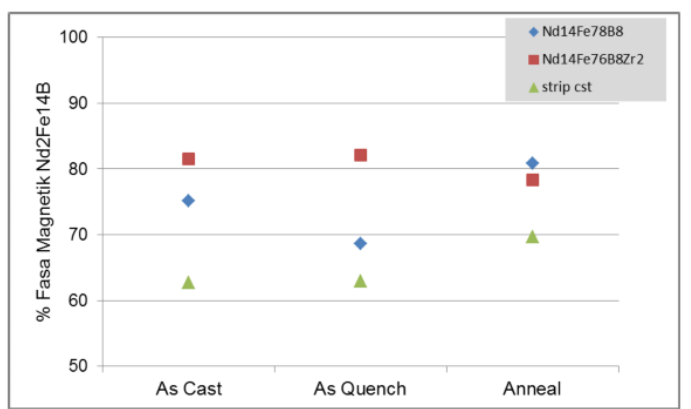

Gambar 2. Hasil analisis quantitative fasa magnetik (software Xpowder)

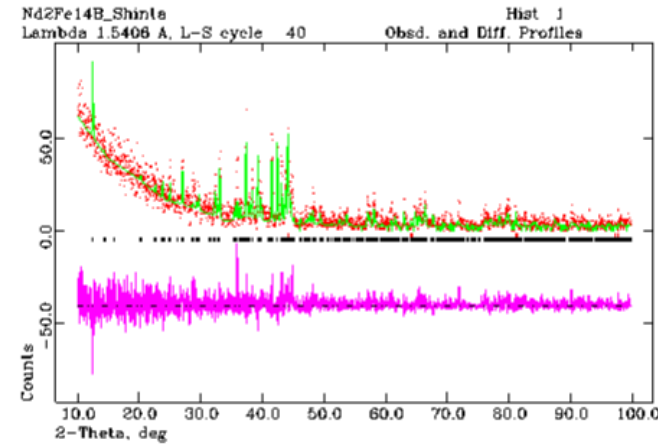

Gambar 3. Hasil quantitative fasa magnetik (software match) + refining GSAS (Fasa $\mathrm{Nd} 2 \mathrm{FeB} 95.5 \%$ + alpha Ferrite $4.5 \%$ ) 


\section{Sifat Magnetik}

Tabel 5 sampai Tabel 7 menunjukkan hasil pengujian sifat magnetik dari ketiga jenis sampel. Hasil pengujian menunjukkan nilai yang cukup rendah tetapi sudah bisa dikatakan memiliki sifat magnet permanen untuk kondisi as cast (> 200 Oe). Tetapi nilai ini masih sangat jauh dari standar magnet $\mathrm{NdFeB}$ yaitu sekitar 9600 Oested (9.6 kOe). Rendahnya sifat magnetik disebabkan oleh oksidasi selama proses penyimpanan dan produksi. Untuk meningkatkan sifat magnetiknya diperlukan handling yang lebih baik.

Tabel 5. Analisis sifat magnetik untuk paduan FeNdB Strip casting (China)

\begin{tabular}{|l|l|l|l|}
\hline & $\mathrm{Br}(\mathrm{kG})$ & $(\mathrm{BH}) \max$ & Hci (kOe) \\
\hline As Received & 1.15 & $<1 \mathrm{MGOe}$ & 0.124 \\
\hline As Cast & 1.32 & $<1 \mathrm{MGOe}$ & 0.221 \\
\hline As Quench & 1.72 & $<1 \mathrm{MGOe}$ & 0.114 \\
\hline As Anneal & 1.38 & $<1 \mathrm{MGO}$ & 0.103 \\
\hline
\end{tabular}

Tabel 6. Analisis Sifat Magnetik untuk paduan $\mathrm{Nd}_{14} \mathrm{Fe}_{78} \mathrm{~B}_{8}$

\begin{tabular}{|l|l|l|l|}
\hline & $\mathrm{Br}(\mathrm{kG})$ & $(\mathrm{BH}) \max$ & Hci (kOe) \\
\hline As Cast & 1.12 & $<1 \mathrm{MGO}$ & 0.246 \\
\hline As Quench & 1.72 & $<1 \mathrm{MGO}$ & 0.114 \\
\hline As Anneal & 1.10 & $<1 \mathrm{MGOe}$ & 0.152 \\
\hline
\end{tabular}

Tabel 7. Analisis Sifat Magnetik untuk paduan

\begin{tabular}{|l|l|l|l|}
\multicolumn{5}{|c}{$N d_{14} \mathrm{Fe}_{76} \mathrm{~B}_{8} \mathrm{Zr}_{2}$} \\
\hline & $\mathrm{Br}(\mathrm{kG})$ & $(\mathrm{BH}) \max$ & Hci (kOe) \\
\hline As Cast & 1.14 & $<1 \mathrm{MGOe}$ & 0.114 \\
\hline As Quench & 1.06 & $<1 \mathrm{MGOe}$ & 0.149 \\
\hline As Anneal & 1.09 & $<1 \mathrm{MGOe}$ & 0.103 \\
\hline
\end{tabular}

\section{KESIMPULAN}

Dari penelitian ini didapatkan beberapa kesimpulan, yaitu:

1. Proses peleburan dengan menggunakan Argon Arc Melting Furnace dapat menghasilkan ingot yang cukup homogen, hanya saja faktor loss dari logam-logam yang dilebur harus diperhitungkan sehingga komposisi yang didapatkan sesuai dengan yang diinginkan.

2. Presentase fasa magnetik dari paduan yang dihasilkan sudah mendekati paduan komersial (> $80 \%)$.

3. Proses Annealing dapat meningkatkan jumlah fasa magnetik dalam paduan $\mathrm{NdFeB}$.
4. Penambahan zircon dalam paduan $\mathrm{NdFeB}$ dapat meningkatkan kestabilan fasa $\mathrm{Nd}_{2} \mathrm{Fe}_{14} \mathrm{~B}$ sehingga tidak diperlukan proses perlakuan panas untuk meningkatkan sifat magnetik.

5. Sifat magnetik yang masih rendah harus ditingkatkan dengan memperbaiki kondisi operasi (vakum atau gas inert).

\section{UCAPAN TERIMA KASIH}

Penelitian ini didanai dari DIPA Pulitbang TIKI Kementrian Perindustrian 2015. Penulis mengucapkan terima kasih kepada Puslitbang Teknologi Industri dan Kekayaan Intelektual Kementerian Perindustrian Republik Indonesia atas terlaksananya penelitian ini.

\section{DAFTAR PUSTAKA}

Aydin, M. (n.d.). Brushless Permanent Magnet Servomotors. Cdn.Intechopen.Com. Retrieved from http://cdn.intechopen.com/ pdfs/34404/InTech-Brushless_permanent_ magnet_servomotors.pdf

Bae, K., Kim, T., Lee, S., Namkung, S., \& Jang, T.-S. (2013). Magnetic and Microstructural Characteristics of a DyF DipCoated Nd-Fe-B Sintered Magnet. IEEE Transactions on Magnetics, 49(7), 32513254. http://doi.org/10.1109/TMAG.2013. 2247574

Ceglarek, A., Płusa, D., \& Pawlik, P. (2012). Structural and magnetic properties of the as-cast $\mathrm{Nd} 10 \mathrm{Fe} 83 \mathrm{Zr} 1 \mathrm{~B} 6$ ribbons, studied by X-ray diffraction and Mössbauer spectroscopy, 58(October), 105-108.

Chae, H. J., \& Kim, T. (n.d.). Extraction of Neodymium from Nd-Fe-B magnet scraps using molten Mg, 55(1984), 2083.

Choi, M., Kim, D., Yu, J., \& Kim, Y. (2011). IMPROVEMENT OF THE MAGNETIC PROPERTIES OF Nd2Fe14B POWDERS BY DYSPROSIUM DIFFUSION. Reviews on Advanced Materials Science, 28, 134-140.

Guruswamy, S., McCarter, M. K., Shield, J. E., \& Panchanathan, V. (1996). Explosive compaction of Magnequench Nd-Fe-B magnetic powders. Journal of Applied Physics, $\quad 79(8), \quad 4851$. http://doi.org/10.1063/1.361631

José, J., \& González, J. (2010). Microstructure and Coercivity Correlationship in Soft 
Magnetic Nanocrystalline Alloys, 16201629.

Kelley, B. J. (n.d.). Permanent Magnet Materials.

Liu, Z. W., Chen, C., Zheng, Z. G., Tan, B. H., \& Ramanujan, R. V. (2011). Phase transitions and hard magnetic properties for rapidly solidified $\mathrm{MnAl}$ alloys doped with $\mathrm{C}, \mathrm{B}$, and rare earth elements. Journal of Materials Science, 47(5), 2333-2338. http://doi.org/10.1007/s10853-011-6049-8

Lupu, N., Grigora, M., Lostun, M., \& Chiriac, H. (1993). Spark Plasma Sintered NdFeBbased Nanocomposite Hard Magnets with Enhanced Magnetic Properties, 3(i).

Magnetism, J. O. F., \& Materials, M. (2011). ナ ノ構造制御機能材料研究部, 23-26.

Manaf, A. (n.d.). Perpustakaan Universitas Indonesia > UI - Laporan Penelitian Karakterisasi dan Pembuatan Magnet Permanen Nd-Fe-B dengan Teknologi Powder Metallurgy dan Rapid Solidification, 650.

Miura, K., Masuda, M., Itoh, M., Horikawa, T., \& Machida, K. (2006). Microwave absorption properties of the nanocomposite powders recovered from $\mathrm{Nd}-$ $\mathrm{Fe}-\mathrm{B}$ bonded magnet scraps. Journal of Alloys and Compounds, 408-412(2006), 1391-1395.

http://doi.org/10.1016/j.jallcom.2005.04.02 5

Sepehri-Amin, H., Ohkubo, T., Nishiuchi, T., Hirosawa, S., \& Hono, K. (2010). Coercivity enhancement of hydrogenationdisproportionation-desorptionrecombination processed $\mathrm{Nd}-\mathrm{Fe}-\mathrm{B}$ powders by the diffusion of $\mathrm{Nd}-\mathrm{Cu}$ eutectic alloys.
Scripta Materialia, 63(11), 1124-1127. http://doi.org/10.1016/j.scriptamat.2010.08 .021

Session, S. (n.d.). THE RARE EARTH ELEMENTS INDUSTRY IN CANADA SUMMARY OF EVIDENCE Standing Committee on Natural Resources, (June 2014).

Shafi, K. V. P. M., Felner, I., Mastai, Y., \& Gedanken, A. (1999). Olympic ring formation from newly prepared barium hexaferrite nanoparticle suspension. Journal of Physical Chemistry B, 103(17), 3358-3360.

http://doi.org/10.1021/JP984691L

Shindo, D., Park, Y. G., Murakami, Y., Gao, Y., Kanekiyo, H., \& Hirosawa, S. (2003). Electron holography of Nd-Fe-B nanocomposite magnets. Scripta Materialia, 48(7), 851-856. http://doi.org/10.1016/S13596462(02)00601-2

Straumal, B. B., Kucheev, Y. O., Yatskovskaya, I. L., Mogilnikova, I. V., Schütz, G., Nekrasov, a. N., \& Baretzky, B. (2012). Grain boundary wetting in the NdFeBbased hard magnetic alloys. Journal of Materials Science, 47(24), 8352-8359. http://doi.org/10.1007/s10853-012-6618-5

Trout, S. R. (1990). Permanet magnets based on the lanthanides. Proceedings of the International Symposium on Magnetics, 79-90. 